Magazine of Concrete Research Volume 63 Issue 2

Effects of CSF content on rheology and cohesiveness of mortar

Kwan and Fung
Magazine of Concrete Research, 2011, 63(2), 99-110

doi: 10.1680/macr.9.00175

Paper 900175

Received 20/092009; last revised 17/02/2010; accepted 11/03/2010.

Published online ahead of print 10/12/2010

Thomas Telford Ltd c 2011
-

\title{
Effects of CSF content on rheology and cohesiveness of mortar
}

\author{
A. K. H. Kwan \\ Department of Civil Engineering, The University of Hong Kong, Hong \\ Kong, China
}

\section{W. W. S. Fung}

Department of Civil Engineering, The University of Hong Kong, Hong Kong, China.

It is widely known that the addition of condensed silica fume to a concrete mix would improve the cohesiveness and hence segregation stability. However, quite often, this would also impair the flowability. To study the overall effects of condensed silica fume, an experimental programme was launched, whereby 45 mortar samples with different condensed silica fume contents and water/solid ratios, each representing the mortar portion of a concrete mix, were tested for their rheological properties, cohesiveness and packing densities. Their rheological properties were measured in terms of flow spread, flow rate, yield stress and apparent viscosity, while their cohesiveness and packing densities were measured using the sieve segregation and wet packing tests respectively. It was found that the effect of condensed silica fume on flowability could be positive or negative, depending on the water/solid ratio, and when the water/solid ratio is low, the addition of condensed silica fume would improve the flowability by increasing the packing density. It was also found that the effect of condensed silica fume on cohesiveness is always positive. Put together, the overall flowability-cohesiveness performance would be improved by the addition of condensed silica fume.

\section{Introduction}

In recent years, the use of high-performance concrete (HPC) has been strongly advocated to enhance the quality of concrete construction (Aïtcin, 1998). However, the mix design of HPC for achieving all-round high performance, especially at the fresh state, is not easy. For a more systematic mix design of HPC, it has been suggested that the mortar portion should first be engineered so as to maximise the performance of the concrete. In this regard, Lachemi et al. (2007) have demonstrated that there is a close relationship between the flowability of a concrete mix and the rheology of its mortar portion. Likewise, $\mathrm{Ng}$ et al. (2009) have found that the flowability of a self-consolidating concrete (SCC) would increase with the flowability of the mortar portion. Hence, proper mix design of the mortar portion is an important step in the development of an HPC.

In general, for an HPC, especially SCC, both high flowability and high segregation stability are desired. To achieve high flowability, the mortar portion has to have high flowability (Lachemi et al., 2007; $\mathrm{Ng}$ et al., 2009) while to achieve high segregation stability, the mortar portion has to have high cohesiveness (Safawi et al., 2004). In other words, the mortar portion should have both high flowability and high cohesiveness. However, these are difficult to achieve simultaneously. Usually, an individual mix design measure that increases the flowability also decreases the cohesiveness and vice versa. For example, the addition of a superplasticiser (SP), particularly the latest polycarboxylate-based type (Gołaszewski and Szwabowski, 2004), could effectively increase the flowability but would also substantially decrease the cohesiveness of mortar. Often, when an SP is added to near its saturation dosage, serious segregation and even dramatic loss of robustness of the concrete occur (Nkinamubanzi and Aitcin, 2004). Hence, care should be taken to avoid excessive reduction in cohesiveness when adding SP to increase the flowability.

On the other hand, the addition of condensed silica fume (CSF) could effectively increase the cohesiveness to improve the segregation stability (Radjy et al., 1986). Rao (2003) explained that the fine particles of CSF would fill into the voids between cement grains and increase the number of contact points between solid particles, thus making the water-solid mixture more cohesive. However, the CSF could also adversely affect the flowability of cement paste/mortar/concrete. Kohno and Komatsu (1986) reported that at the same water/binder ratio and SP dosage, a mortar containing CSF would have smaller flow compared with a plain mortar with no CSF. Khatri et al. (1995) found that the SP dosage for a concrete has to be increased when CSF is added in order to maintain the same level of workability. Park et al. (2005) measured the yield stress and viscosity of cement pastes containing CSF and found that these rheological properties would increase with the CSF content. More recently, Artelt and Garcia (2008) examined a number of mortar mixes with and without CSF and concluded that the presence of CSF would impair the workability as evidenced by the smaller flow spread and longer flow time of the CSF mortars. 
Nevertheless, beneficial effects of CSF on the flowability have also been reported. Duval and Kadri (1998) examined a number of concrete mixes with CSF contents varying from 0 to $30 \%$ by weight and found that the concrete mix with $10 \%$ CSF content would, among the others, have the lowest required SP dosage for the same slump. Zhang and Han (2000) showed that the yield stress and viscosity of a cement paste could be decreased if CSF is added to replace $10 \%$ by weight of cement. Rao (2003) conducted a similar study on mortar and found that at a constant water/binder ratio equal to 0.45 or 0.50 , the flow of mortar would initially increase with the CSF content until a maximum value is reached at a CSF content of about 10 to $15 \%$ by weight and then decrease upon further increase of the CSF content. More recently, Vikan and Justnes (2007) found that the flow resistance of a cement paste could be reduced by adding CSF to replace $10 \%$ by volume of cement.

The different results obtained by different researchers indicate that the effects of CSF on the flowability are by no means straightforward. In theory, the addition of CSF should have two effects. First, the fine CSF particles would fill into the voids between cement grains to increase the packing density of the cementitious materials. With the packing density increased, the volume of voids to be filled with water would be decreased and the amount of excess water (water in excess of that needed to fill up the voids) available for lubrication would be increased. Second, owing to the high fineness of CSF, the addition of CSF would markedly increase the surface area of the solid particles in the water-solid mixture and thus for the same amount of excess water, the thickness of the water films coating the solid particles would be decreased. The increase in packing density and the increase in surface area have opposite effects on the flowability and their net influence is dependent on the relative magnitudes of these effects. However, this theory has for a long time remained just as a postulation because of the lack of a suitable test method for direct measurement of the packing density of solid particles in cement paste or mortar. Recently, a wet packing test for direct measurement of packing density has been developed by Wong and Kwan (2008), Fung et al. (2009) and Kwan and Fung (2009). Hopefully, with the packing density directly measured, the effects of CSF could be more scientifically studied.

Meanwhile, although it is generally accepted that the addition of CSF could increase the cohesiveness, a suitable test method for measuring the cohesiveness of cement paste and mortar is still lacking. For measuring the segregation stability (usually taken as a measure of cohesiveness) of a concrete mix containing coarse aggregate, the sieve segregation test has been widely used, as stipulated in the European Guidelines for SCC (SCC European Project Group, 2005). Domone (2006) employed a slightly modified version of the sieve segregation test to measure the stability of mortar. As mortar does not contain any coarse aggregate, he used a $1.0 \mathrm{~mm}$ sieve instead of the $5.0 \mathrm{~mm}$ sieve recommended by the European Guidelines. This modified sieve segregation test appears to be a suitable test for assessing the cohesiveness of mortar and should have the potential of becoming a standard test.

By and large, the addition of CSF can surely enhance cohesiveness but its effect on flowability is not so certain. The authors are of the view that if used properly, CSF can increase the flowability and cohesiveness simultaneously. To find out how and why, more scientific and systematic studies are needed. For this purpose, a comprehensive testing programme was carried out, in which 45 mortar samples with CSF contents varying from 0 to $25 \%$ by volume and different water contents were made for in-depth examination, as reported herein. The rheological properties of the mortars were measured in terms of flow spread, flow rate, yield stress and apparent viscosity, while their cohesiveness and packing densities were measured using the sieve segregation and wet packing tests, respectively.

\section{Testing programme}

To study the effects of CSF, six different CSF contents, namely $0,5,10,15,20$ and $25 \%$ by volume of the total cementitious materials, were adopted for the design of the mortar mixes. To exclude the effect of fine aggregate, the ratio of total cementitious materials to fine aggregate was fixed at 0.75 by volume. As the effects of CSF are dependent on the water content, the water/ solid (w/s) ratio by volume was varied in steps of 0.05 from 0.35 to 0.65 for CSF contents of 0,5 and $10 \%$ and from 0.35 to 0.70 for CSF contents of 15, 20 and $25 \%$ (the solid volume is the volume of cementitious materials plus fine aggregate). In total, 45 mortar samples were produced for testing. An SP was added to each mortar sample at a dosage of $93.3 \mathrm{~kg} / \mathrm{m}^{3}$ by liquid mass of the SP to the solid volume of the cementitious materials, which is the upper limit of normal dosage recommended by the supplier. For easy identification, each mortar sample is assigned a designation of $\mathrm{X}-\mathrm{Y}$, where $\mathrm{X}$ denotes the CSF content $(\mathrm{A}=0 \%, \mathrm{~B}=5 \%, \mathrm{C}=10 \%, \mathrm{D}=15 \%, \mathrm{E}=20 \%$ and $\mathrm{F}=25 \%)$ and $\mathrm{Y}$ denotes the $\mathrm{w} / \mathrm{s}$ ratio, as listed in Table 1. For example, B0.50 designates the mortar sample with a CSF content of $5 \%$ and a $\mathrm{w} / \mathrm{s}$ ratio of $0 \cdot 50$.

Each mortar sample was produced using a standard mixer by first adding all the water to the mixer and then adding the solid materials bit by bit to the mixer while mixing. This mixing procedure has been found to be more effective than the conventional mixing procedure of adding all the water and solid materials to the mixer in a single batch, especially when the water content is low and/or the CSF content is high (Fung et al., 2009; Kwan and Fung, 2009; Wong and Kwan, 2008). By doing so, a slurry is formed at the beginning. As more and more solids are added, the slurry is gradually turned into a lump of oversaturated mixture. When further solids are added by spreading it evenly to the mixture, the solids are very soon wetted and intermixed with the mixture. As the degree of saturation decreases, the mixing becomes more difficult, but the total mixing time needed is still much shorter than that required with the use of the conventional mixing procedure. The mortar samples so produced were then 
Magazine of Concrete Research

Volume 63 Issue 2
Effects of CSF content on rheology and

cohesiveness of mortar

Kwan and Fung

\begin{tabular}{|c|c|c|c|}
\hline Sample No. & CSF content: \% & w/s ratio & Packing density \\
\hline$A-0 \cdot 35$ & 0 & 0.35 & 0.712 \\
\hline$A-0 \cdot 40$ & & $0 \cdot 40$ & \\
\hline A- 0.45 & & 0.45 & \\
\hline$A-0.50$ & & 0.50 & \\
\hline$A-0.55$ & & 0.55 & \\
\hline A- 0.60 & & 0.60 & \\
\hline A- 0.65 & & 0.65 & \\
\hline$B-0 \cdot 35$ & 5 & $0 \cdot 35$ & 0.721 \\
\hline$B-0 \cdot 40$ & & 0.40 & \\
\hline$B-0 \cdot 45$ & & 0.45 & \\
\hline$B-0 \cdot 50$ & & 0.50 & \\
\hline$B-0 \cdot 55$ & & 0.55 & \\
\hline$B-0 \cdot 60$ & & 0.60 & \\
\hline$B-0.65$ & & 0.65 & \\
\hline$C-0.35$ & 10 & 0.35 & 0.734 \\
\hline$C-0.40$ & & 0.40 & \\
\hline$C-0.45$ & & 0.45 & \\
\hline$C-0.50$ & & 0.50 & \\
\hline$C-0.55$ & & 0.55 & \\
\hline$C-0.60$ & & 0.60 & \\
\hline$C-0.65$ & & 0.65 & \\
\hline D-0.35 & 15 & 0.35 & 0.743 \\
\hline D-0.40 & & 0.40 & \\
\hline$D-0.45$ & & 0.45 & \\
\hline$D-0 \cdot 50$ & & 0.50 & \\
\hline D-0.55 & & 0.55 & \\
\hline D-0.60 & & 0.60 & \\
\hline D-0.65 & & 0.65 & \\
\hline D-0.70 & & $0 \cdot 70$ & \\
\hline$E-0.35$ & 20 & 0.35 & 0.757 \\
\hline$E-0 \cdot 40$ & & $0 \cdot 40$ & \\
\hline$E-0.45$ & & 0.45 & \\
\hline$E-0 \cdot 50$ & & 0.50 & \\
\hline$E-0.55$ & & 0.55 & \\
\hline$E-0.60$ & & 0.60 & \\
\hline$E-0.65$ & & 0.65 & \\
\hline$E-0 \cdot 70$ & & $0 \cdot 70$ & \\
\hline $\mathrm{F}-0.35$ & 25 & 0.35 & 0.767 \\
\hline$F-0 \cdot 40$ & & $0 \cdot 40$ & \\
\hline$F-0 \cdot 45$ & & $0 \cdot 45$ & \\
\hline$F-0 \cdot 50$ & & 0.50 & \\
\hline $\mathrm{F}-0.55$ & & 0.55 & \\
\hline$F-0.60$ & & 0.60 & \\
\hline F-0.65 & & 0.65 & \\
\hline $\mathrm{F}-0.70$ & & 0.70 & \\
\hline
\end{tabular}

Table 1. Mix parameters and packing density results of the mortar samples

tested for their rheological properties and cohesiveness. For the measurement of packing density, the wet packing test was carried out on another set of mortar samples produced using the same mixer by the same mixing procedure.

\section{Materials}

An ordinary Portland cement (OPC) of strength class $52 \cdot 5 \mathrm{~N}$ and a CSF were used as the only cementitious materials. The OPC used was obtained from the local market and had been tested to comply with BS 12 (BSI, 1996) while the CSF used was imported from Norway and had been tested by the supplier to comply with ASTM C 1240-03 (ASTM, 2003). As for the fine aggregate, local crushed granite rock fine with a maximum size of $1.18 \mathrm{~mm}$ and a water absorption of $1.6 \%$ by mass was used. The relative densities of the OPC, CSF and fine aggregate had been measured in accordance with BS 812: Part 2 (BSI, 1995) as 3.11, $2 \cdot 20$ and 2.66 respectively. A laser diffraction particle size analyser was used to measure the particle size distributions of the materials and the results are plotted in Figure 1. The specific surface area of the OPC was calculated based on its Blaine fineness to be $1.07 \times 10^{6} \mathrm{~m}^{2} / \mathrm{m}^{3}$, while the specific surface areas of the CSF and fine aggregate were calculated based on their particle size distributions to be $13.3 \times 10^{6} \mathrm{~m}^{2} / \mathrm{m}^{3}$ and $0.21 \times 10^{6} \mathrm{~m}^{2} / \mathrm{m}^{3}$ respectively. The SP employed was a polycarboxylate-based type with a solid mass content of $20 \%$ and a relative density of 1.03 .

\section{Measuring packing density}

The wet packing test recently developed by the present authors' research group for cementitious materials (Wong and Kwan, 2008), fine aggregate (Fung et al., 2009) and cementitious materials plus fine aggregate (Kwan and Fung, 2009) was used to measure the packing density of the solid particles (mixture of cementitious materials and fine aggregate) in the mortar. In principle, the wet packing test measures the solid concentrations of the mortar samples produced at different $w / s$ ratios and determines the packing density of the solid particles under wet condition as the maximum solid concentration so obtained. Compared with the existing dry packing test for fine and coarse aggregates stipulated in BS 812: Part 2 (BSI, 1995), this wet packing test has the overwhelming advantage that the effects of water and SP (if any) are incorporated because the packing

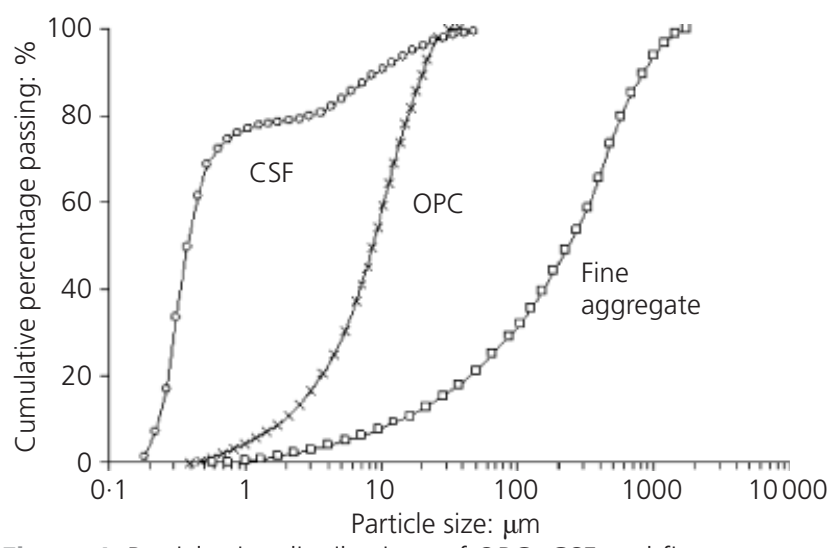

Figure 1. Particle size distributions of OPC, CSF and fine aggregate 
density measurement is conducted with water and SP (if any) added.

Since the cementitious materials/fine aggregate ratio was fixed, the 45 mortar samples were actually made from six different mixes of cementitious materials and fine aggregate. The six mixes are numbered from $\mathrm{A}$ to $\mathrm{F}$ and have CSF contents of $0,5,10,15$, 20 and $25 \%$ respectively. For each mix, eight to ten mortar samples were produced at different $\mathrm{w} / \mathrm{s}$ ratios. The same SP at the same dosage of $93.3 \mathrm{~kg} / \mathrm{m}^{3}$ of the volume of cementitious materials was added to each mortar sample. After mixing by the same procedure as mentioned before, the solid concentrations of the mortar samples were measured and the maximum solid concentration so obtained was taken as the packing density of the mix of cementitious materials and fine aggregate.

\section{Measuring flow spread and flow rate}

The mini slump cone test and mini V-funnel test were used to measure the flow spread and flow rate, respectively, of the mortar samples. Both the mini slump cone and mini V-funnel tests for mortar may be regarded as reduced scale versions of the slump and V-funnel tests for concrete.

There are several versions of mini slump cone test employing slump cones of different dimensions. The version adopted herein is the same as that used by Okamura and Ouchi (2003), which employs a slump cone of dimensions as shown in Figure 2(a). The test procedures are outlined below.

(a) Place the slump cone at the centre of a flat, smooth and level steel plate.

(b) Pour the mortar into the slump cone until the slump cone is completely filled up and trowel flat the top surface of the mortar.

(c) Lift the slump cone gently and allow the mortar to flow and spread for at least $3 \mathrm{~min}$.

(d) Measure two perpendicular diameters of the mortar patty formed, calculate the average diameter and determine the flow spread of the mortar as the average diameter minus the base diameter of the slump cone.

Likewise, there are several versions of mini V-funnel test employing V-funnels of different dimensions. The version adopted herein is the same as that used by Okamura and Ouchi (2003), which employs a V-funnel of dimensions as shown in Figure 2(b). The test procedures are detailed below.

(a) Mount the V-funnel on a stable stand and close the opening of the V-funnel at the bottom.

(b) Pour the mortar into the V-funnel until the V-funnel is

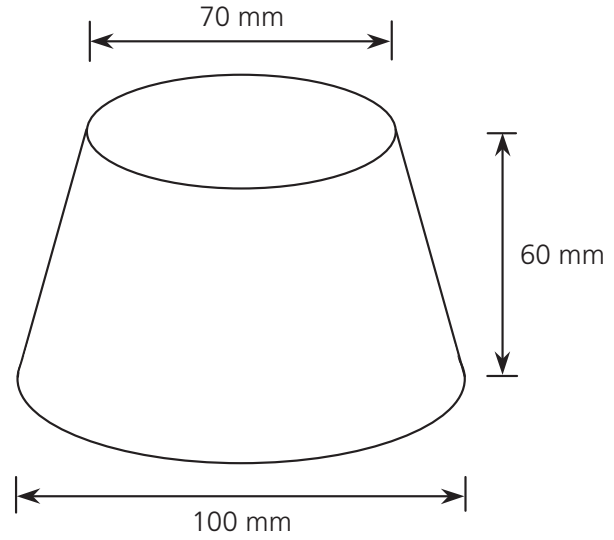

(a)

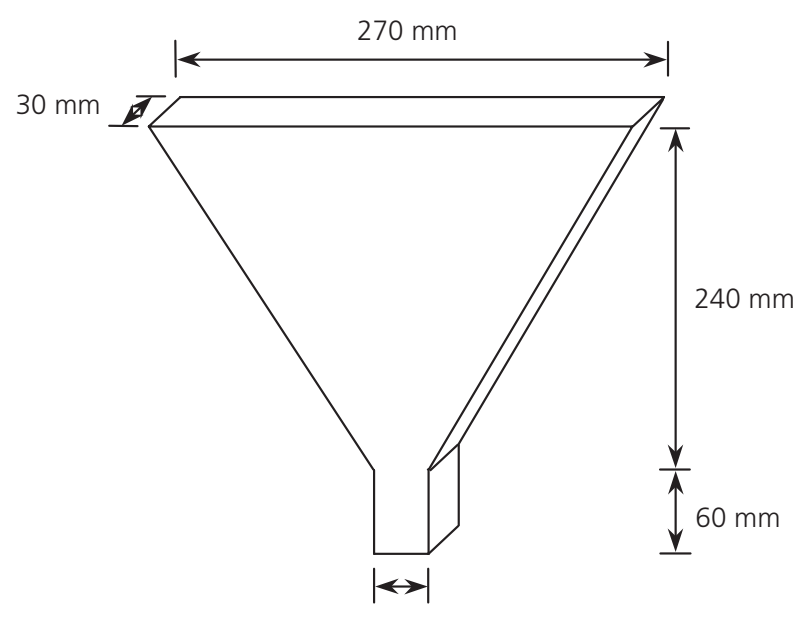

$30 \mathrm{~mm}$

(b)

Figure 2. (a) Mini slump cone; (b) mini V-funnel

completely filled up. To minimise air entrapment, pour the mortar slowly along the inner surfaces of the V-funnel.

(c) Open the opening of the V-funnel to let the mortar flow out. Record the time from the start of the flow to the first sight of light through the opening. The recorded time is the flow time of the mortar. Calculate the flow rate as the volume of mortar sample (equal to $1134 \mathrm{ml}$ ) divided by the flow time.

\section{Measuring rheological properties}

The vane test was used to evaluate the rheological properties of the mortar samples. It was carried out using a speed-controlled rheometer equipped with a shear vane, measuring $20 \mathrm{~mm}$ in width and $40 \mathrm{~mm}$ in length, and a cylindrical container, having an inner diameter of $40 \mathrm{~mm}$, as shown in Figure 3. The inner wall of the container was profiled with grooves in such a way that the asperity was larger than the largest particle in the mortar sample being tested. This was to minimise slippage of the mortar at the container surface during shearing. 
Effects of CSF content on rheology and

cohesiveness of mortar

Kwan and Fung

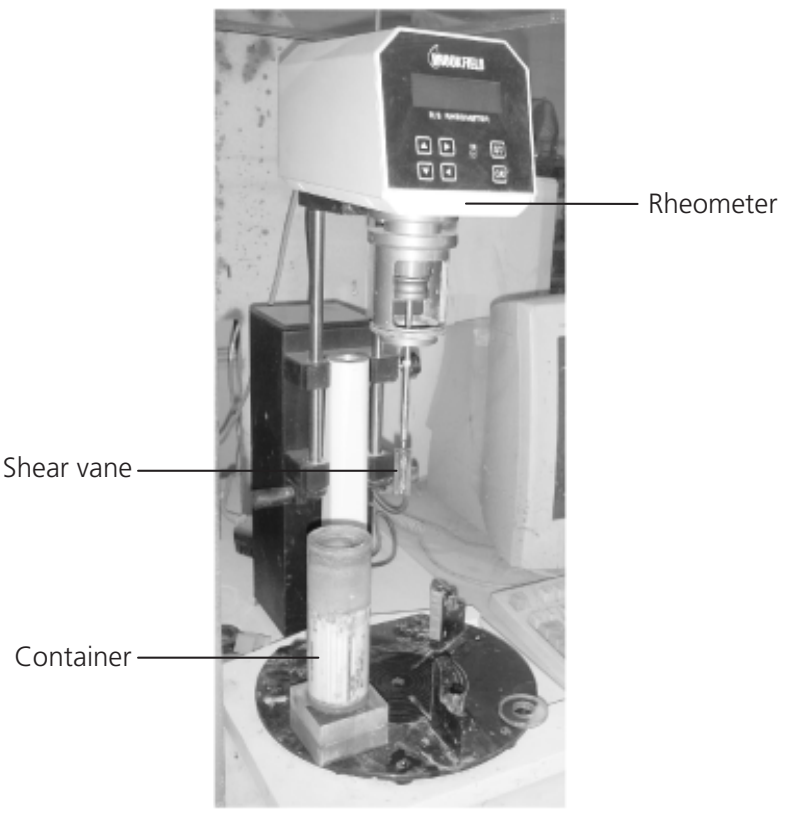

Figure 3. Rheometer, shear vane and container

At the onset of the test, the shear vane was concentrically inserted into the mortar sample in the cylindrical container and then set to rotate at controlled rotation speed, following a shearing sequence which consisted of two shearing cycles. The first cycle, called the pre-shearing cycle, was to apply pre-shearing to the sample so that all the samples tested had the same shearing history before measurement. The second cycle, called the data-logging cycle, was for the actual measurement. In the data-logging cycle, the rotation speed $N$ (measured in terms of $\mathrm{r} / \mathrm{min}$, i.e. rotation per minute) was increased from 0 to $50 \mathrm{r} / \mathrm{min}$ in $75 \mathrm{~s}$ and then decreased to $0 \mathrm{r} / \mathrm{min}$ in another $75 \mathrm{~s}$. During shearing, the torque $T$ (measured in terms of $\mathrm{mNm}$ ) induced at the shear vane was continuously monitored and regularly logged by a computer. The results obtained at decreasing rotation speed, which are generally more consistent and repeatable, were used for evaluating the rheological properties of the mortar sample.

As the mortar is non-Newtonian, it is customary to describe its rheological properties by either the Bingham model (which assumes that the shear stress-shear rate curve is linear) or the Herschel-Bulkley model (which assumes that the shear stressshear rate curve follows the power equation). Upon curve fitting using both models, it was found that the experimental results agreed better with the Herschel-Bulkley model, whose shear stress-shear rate relation is given by

1. $\tau=\tau_{0}+k \dot{\gamma}^{n}$

where $\tau$ is shear stress (Pa), $\dot{\gamma}$ is shear rate $\left(\mathrm{s}^{-1}\right), \tau_{0}$ is yield stress $(\mathrm{Pa})$, and $k\left(\mathrm{Pas}^{\mathrm{n}}\right)$ and $n$ (non-dimensional) are empirical coefficients. To evaluate the rheological properties of the mortar sample tested, the best-fit curve based on the above equation was first obtained by regression analysis. Then, from the best-fit curve so obtained, the yield stress (taken as the shear stress at a shear rate of zero) and apparent viscosity (taken as the ratio of shear stress to shear rate at a shear rate of $14 / \mathrm{s}$ ) were determined to characterise the rheology of the mortar sample.

\section{Measuring cohesiveness}

The cohesiveness of the mortar samples was measured using a modified version of the sieve segregation test stipulated in the European Guidelines for SCC (SCC European Project Group, 2005). This modified sieve segregation test for mortar is similar to the sieve segregation test for SCC except that a smaller $1.18 \mathrm{~mm}$ sieve is used instead of the $5.0 \mathrm{~mm}$ sieve for SCC.

To carry out the test, an approximately $0 \cdot 2$ litre mortar sample was poured onto the $1.18 \mathrm{~mm}$ sieve from a height of $300 \mathrm{~mm}$. Part of the mortar would then drip through the sieve depending on the cohesiveness of the mortar. After 2 min, the mortar dripped through the sieve and collected by a base receiver was weighed. For a mortar with low cohesiveness, nearly all the mortar poured onto the sieve would drip through the sieve. On the contrary, for a mortar with high cohesiveness, only a small amount of mortar would drip through the sieve. For this reason, the proportion of mortar dripping through the sieve may be taken as a measure of cohesiveness. Following the sieve segregation test for SCC, the sieve segregation index (SSI) of the mortar sample tested may be determined as

2. $\mathrm{SSI}=\frac{M_{\mathrm{p}}}{M_{\mathrm{m}}} \times 100 \%$

in which $M_{\mathrm{p}}$ is the mass of mortar collected by the base receiver, and $M_{\mathrm{m}}$ is the mass of mortar poured onto the sieve. A low SSI indicates high cohesiveness whereas a high SSI indicates low cohesiveness.

\section{Results and discussions}

\section{Packing density}

The packing density results of the six mixes of cementitious materials and fine aggregate tested are tabulated in the last column of Table 1. From these results, it can be seen that every mix containing CSF has a higher packing density than the one containing no CSF. This may be attributed to the filling effect of the CSF particles. Because of their small size, the CSF particles filled themselves into the voids between the OPC and fine aggregate particles and thus increased the solid concentration of mix of cementitious materials and fine aggregate. Furthermore, it can also be seen that the packing density increased almost linearly with the CSF content up to a CSF content of $25 \%$. More specifically, with $25 \%$ CSF added, the packing density of the mix was increased from 0.712 to $0 \cdot 767$. Such an increase in packing density of about $8 \%$ may not seem much at first sight but is 
significant enough to change the rheology of the mortar formed, as will be depicted in the following sections.

\section{Flow spread and flow rate}

The flow spread and flow rate results of the mortar samples are tabulated in the second and third columns of Table 2, and plotted against the w/s ratio in Figure 4. It is evident that both the flow spread and flow rate increased with the $\mathrm{w} / \mathrm{s}$ ratio. These observed phenomena are expected, as it is well known that increasing the water content of a mortar would improve the flowability. It is also noted that at the same w/s ratio, both the flow spread and flow rate varied with the CSF content. This is depicted by the different curves plotted for the mortar samples with different CSF contents. However, the variations of the flow spread and flow rate with the CSF appeared to be quite complicated and dependent on the $\mathrm{w} / \mathrm{s}$ ratio.

Compared with the flow spread, the flow rate may be a better measure of flowability. This is manifested by the results that were obtained within the range of mixes covered in this study, namely the flow rate varied widely from $50 \mathrm{ml} / \mathrm{s}$ to more than $600 \mathrm{ml} / \mathrm{s}$ while the flow spread varied merely from $200 \mathrm{~mm}$ to about $300 \mathrm{~mm}$ and stayed at around $300 \mathrm{~mm}$ even when the flowability further increased. This means that when the mortar to be tested is
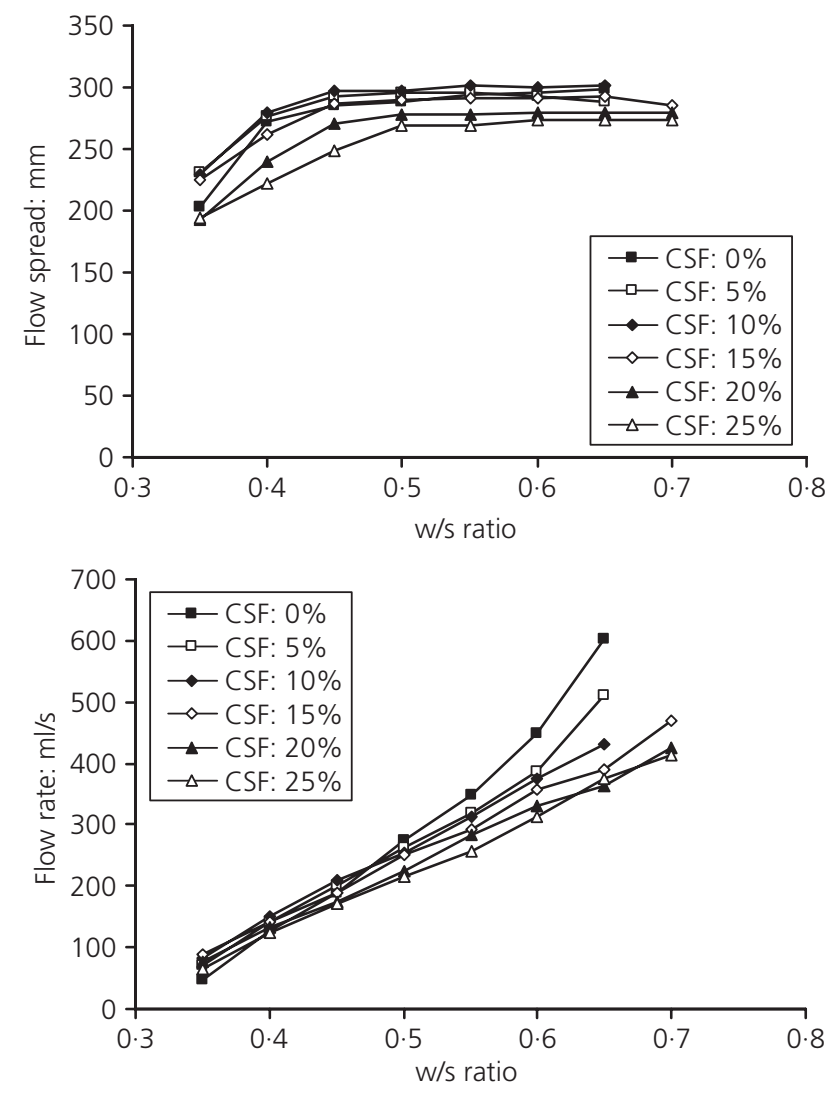

Figure 4. Flowability plotted against w/s ratio highly flowable, the flow spread measurement would not be sensitive enough to reveal any change in flowability.

\section{Yield stress and apparent viscosity}

The yield stress and apparent viscosity results of the mortar samples are tabulated in the fourth and fifth columns of Table 2, and plotted against the w/s ratio in Figure 5. From the curves plotted, it can be seen that both these rheological properties gradually decreased as the w/s ratio increased. This agrees with the general observation that increasing the water content of a mortar would reduce the yield stress and apparent viscosity. It can also be seen that at the same w/s ratio, both these rheological properties varied with the CSF content, as illustrated by the different curves plotted for the mortar samples with different CSF contents. Hence, it may be concluded that the rheological properties of a mortar are governed not just by the water content but also by the mix composition of the solid particles in the mortar, especially the CSF content.

\section{Sieve segregation index}

The SSI results of the mortar samples are tabulated in the last column of Table 2 and plotted against the w/s ratio in Figure 6. It is seen that the SSI increased gradually with the $\mathrm{w} / \mathrm{s}$ ratio, implying that a mortar with a higher $\mathrm{w} / \mathrm{s}$ ratio would tend to have
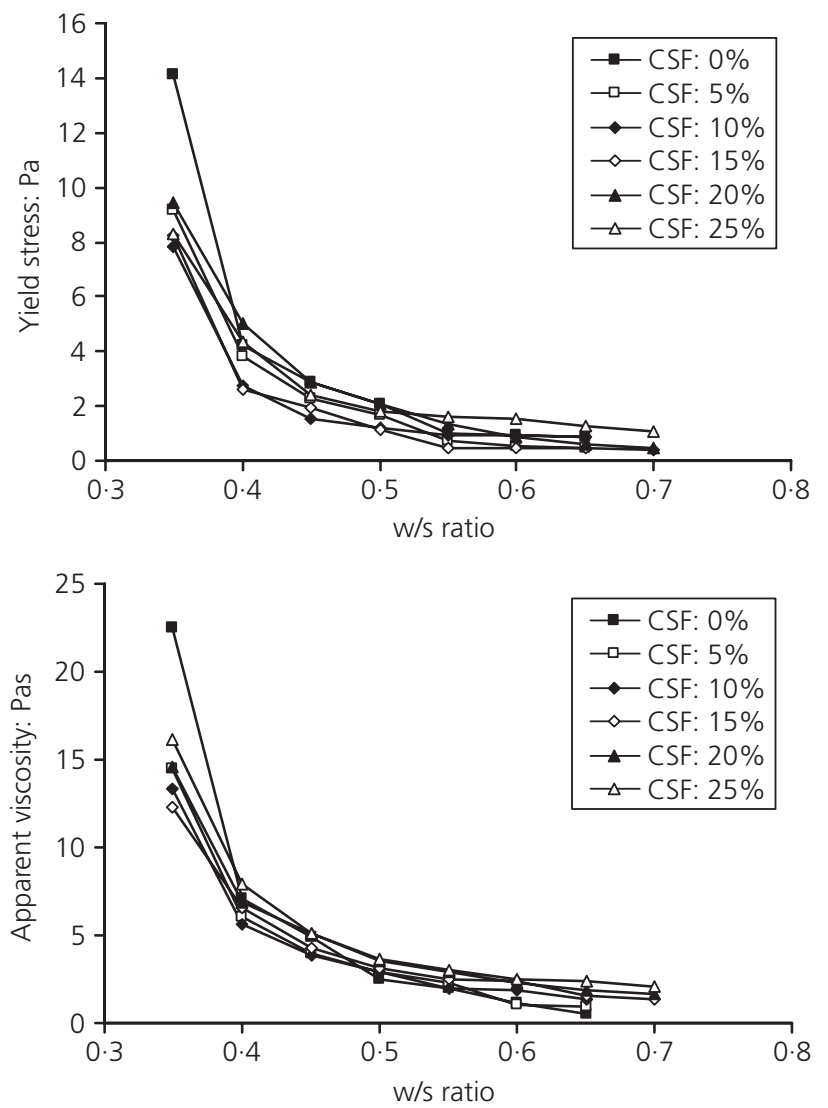

Figure 5. Rheological properties plotted against w/s ratio 


\begin{tabular}{|c|c|c|c|c|c|}
\hline Sample No. & Flow spread: mm & Flow rate: $\mathrm{ml} / \mathrm{s}$ & Yield stress: Pa & $\begin{array}{c}\text { Apparent viscosity: } \\
\text { Pas }\end{array}$ & SSI: \% \\
\hline$A-0 \cdot 35$ & 204 & 48 & $14 \cdot 12$ & $22 \cdot 52$ & 0.0 \\
\hline$A-0 \cdot 40$ & 272 & 127 & $4 \cdot 24$ & $7 \cdot 08$ & $1 \cdot 4$ \\
\hline A- 0.45 & 286 & 188 & $2 \cdot 86$ & $4 \cdot 85$ & $11 \cdot 2$ \\
\hline$A-0 \cdot 50$ & 288 & 275 & 2.09 & $2 \cdot 52$ & $14 \cdot 9$ \\
\hline$A-0 \cdot 55$ & 294 & 350 & 1.00 & $2 \cdot 02$ & $24 \cdot 0$ \\
\hline$A-0.60$ & 295 & 450 & 0.95 & $1 \cdot 15$ & $34 \cdot 0$ \\
\hline A- -0.65 & 298 & 603 & 0.85 & 0.50 & $40 \cdot 0$ \\
\hline B- 0.35 & 231 & 71 & $9 \cdot 20$ & $14 \cdot 50$ & 0.0 \\
\hline$B-0 \cdot 40$ & 276 & 142 & 3.83 & 6.03 & 0.5 \\
\hline$B-0 \cdot 45$ & 293 & 202 & $2 \cdot 30$ & 3.99 & $7 \cdot 7$ \\
\hline$B-0 \cdot 50$ & 296 & 263 & 1.64 & $2 \cdot 87$ & $9 \cdot 4$ \\
\hline$B-0.55$ & 295 & 318 & 0.73 & $2 \cdot 26$ & $12 \cdot 1$ \\
\hline$B-0 \cdot 60$ & 293 & 387 & 0.54 & 1.07 & $15 \cdot 0$ \\
\hline$B-0 \cdot 65$ & 288 & 511 & 0.50 & 0.99 & $19 \cdot 0$ \\
\hline$C-0.35$ & 230 & 82 & $7 \cdot 83$ & $13 \cdot 30$ & 0.0 \\
\hline$C-0 \cdot 40$ & 280 & 151 & $2 \cdot 75$ & $5 \cdot 60$ & 0.2 \\
\hline C- -0.45 & 297 & 210 & $1 \cdot 51$ & 3.89 & $5 \cdot 5$ \\
\hline$C-0 \cdot 50$ & 297 & 255 & $1 \cdot 20$ & $2 \cdot 94$ & $8 \cdot 3$ \\
\hline C-0.55 & 302 & 312 & 0.93 & 2.02 & 9.5 \\
\hline C- -0.60 & 300 & 374 & 0.92 & $1 \cdot 87$ & $11 \cdot 2$ \\
\hline C-0.65 & 302 & 431 & 0.90 & $1 \cdot 35$ & $16 \cdot 1$ \\
\hline$D-0 \cdot 35$ & 225 & 88 & 8.25 & $12 \cdot 30$ & 0.0 \\
\hline D- 0.40 & 265 & 142 & $2 \cdot 59$ & $6 \cdot 58$ & 0.0 \\
\hline D- 0.45 & 287 & 189 & 1.93 & $4 \cdot 32$ & 1.6 \\
\hline D- 0.50 & 290 & 252 & $1 \cdot 12$ & 3.08 & $4 \cdot 4$ \\
\hline D- 0.55 & 291 & 292 & 0.50 & $2 \cdot 45$ & $6 \cdot 3$ \\
\hline D- 0.60 & 291 & 359 & 0.50 & $2 \cdot 43$ & $9 \cdot 2$ \\
\hline D-0.65 & 292 & 391 & 0.47 & 1.57 & $10 \cdot 3$ \\
\hline D- 0.70 & 285 & 471 & 0.40 & $1 \cdot 31$ & $11 \cdot 3$ \\
\hline$E-0.35$ & 193 & 76 & $9 \cdot 44$ & $14 \cdot 56$ & 0.0 \\
\hline$E-0.40$ & 240 & 133 & 5.00 & 6.88 & 0.1 \\
\hline$E-0.45$ & 270 & 175 & $2 \cdot 90$ & $5 \cdot 10$ & 0.2 \\
\hline$E-0.50$ & 278 & 224 & 2.07 & $3 \cdot 58$ & $2 \cdot 7$ \\
\hline$E-0.55$ & 278 & 284 & $1 \cdot 36$ & $2 \cdot 92$ & $3 \cdot 8$ \\
\hline$E-0.60$ & 280 & 330 & 0.89 & $2 \cdot 29$ & $4 \cdot 1$ \\
\hline$E-0.65$ & 280 & 363 & 0.60 & $1 \cdot 89$ & $5 \cdot 2$ \\
\hline$E-0 \cdot 70$ & 280 & 426 & 0.48 & $1 \cdot 70$ & $6 \cdot 7$ \\
\hline$F-0.35$ & 195 & 66 & $8 \cdot 30$ & $16 \cdot 11$ & 0.0 \\
\hline$F-0.40$ & 222 & 125 & $4 \cdot 35$ & $7 \cdot 91$ & 0.1 \\
\hline$F-0.45$ & 249 & 170 & $2 \cdot 39$ & $5 \cdot 10$ & $0 \cdot 1$ \\
\hline$F-0.50$ & 269 & 216 & $1 \cdot 81$ & 3.69 & $1 \cdot 2$ \\
\hline$F-0.55$ & 269 & 257 & 1.61 & 3.01 & $3 \cdot 1$ \\
\hline$F-0.60$ & 274 & 312 & 1.55 & $2 \cdot 50$ & $4 \cdot 0$ \\
\hline$F-0.65$ & 274 & 374 & $1 \cdot 27$ & $2 \cdot 36$ & $4 \cdot 7$ \\
\hline $\mathrm{F}-0 \cdot 70$ & 274 & 412 & $1 \cdot 10$ & 2.04 & $5 \cdot 6$ \\
\hline
\end{tabular}




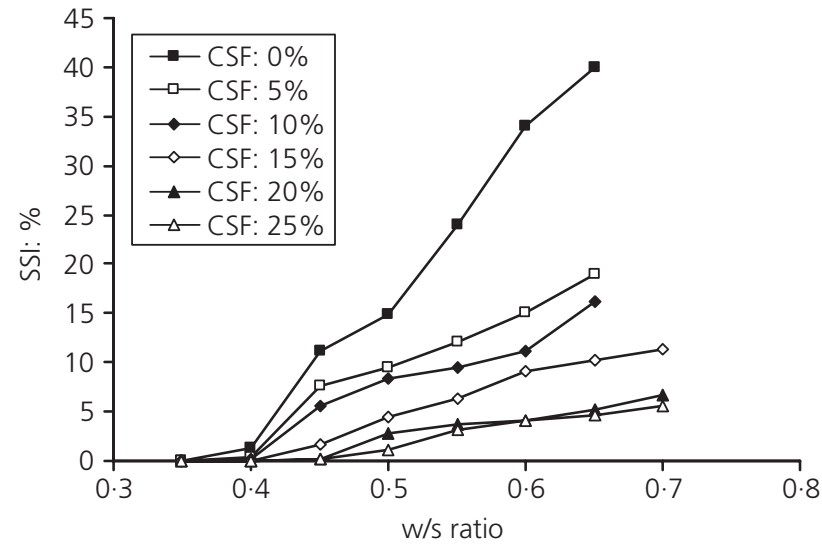

Figure 6. Sieve segregation index plotted against w/s ratio

a lower cohesiveness. This phenomenon can be easily understood, as increasing the $\mathrm{w} / \mathrm{s}$ ratio would decrease the solid concentration and result in a thinner water-solid mixture. It is also seen from the widely separated curves plotted for the mortar samples with different CSF contents that the effect of CSF on cohesiveness was quite substantial. For example, at a w/s ratio of 0.65 , the SSI of the mortar without CSF was $40 \%$ while the SSI of the mortar with $5 \%$ CSF content was only $19 \%$. These results demonstrate very clearly that CSF is highly effective in improving the cohesiveness of mortar.

\section{Effects of CSF}

To better study the effects of CSF on the flowability, the flow spread and flow rate results are plotted against the CSF content in Figure 7. The flow spread-CSF content curves show that as the CSF content increased from $0 \%$ onwards, the flow spread first increased to a maximum value at an optimum CSF content of around $10 \%$ and then decreased. Such effect of CSF on flow spread was smaller at a higher $\mathrm{w} / \mathrm{s}$ ratio and became minimal at $\mathrm{w} / \mathrm{s}$ ratios higher than $0 \cdot 50$. On the other hand, the flow rate-CSF content curves show that at a w/s ratio equal to $0.35,0.40$ or 0.45 , the flow rate first increased with the CSF content until the CSF content reached a certain optimum value of around 10 to $15 \%$ and then decreased as the CSF content further increased. However, at a w/s ratio equal to 0.50 or higher, the flow rate never increased but started right at the beginning to decrease as the CSF content increased from $0 \%$ onwards. On the whole, it may be concluded that the effects of CSF on flowability are dependent on the $\mathrm{w} / \mathrm{s}$ ratio and that at a w/s ratio lower than 0.50 , the addition of CSF can improve the flowability whereas at a w/s ratio higher than $0 \cdot 50$, the addition of CSF has either little effect or a slight adverse effect on the flowability. CSF is particularly useful when the water content is low because it can increase not only the strength but also the flowability of the mortar.

Similarly, the yield stress and apparent viscosity results are plotted against the CSF content in Figure 8 to study the effects of CSF. The yield stress-CSF content curves reveal that as the CSF
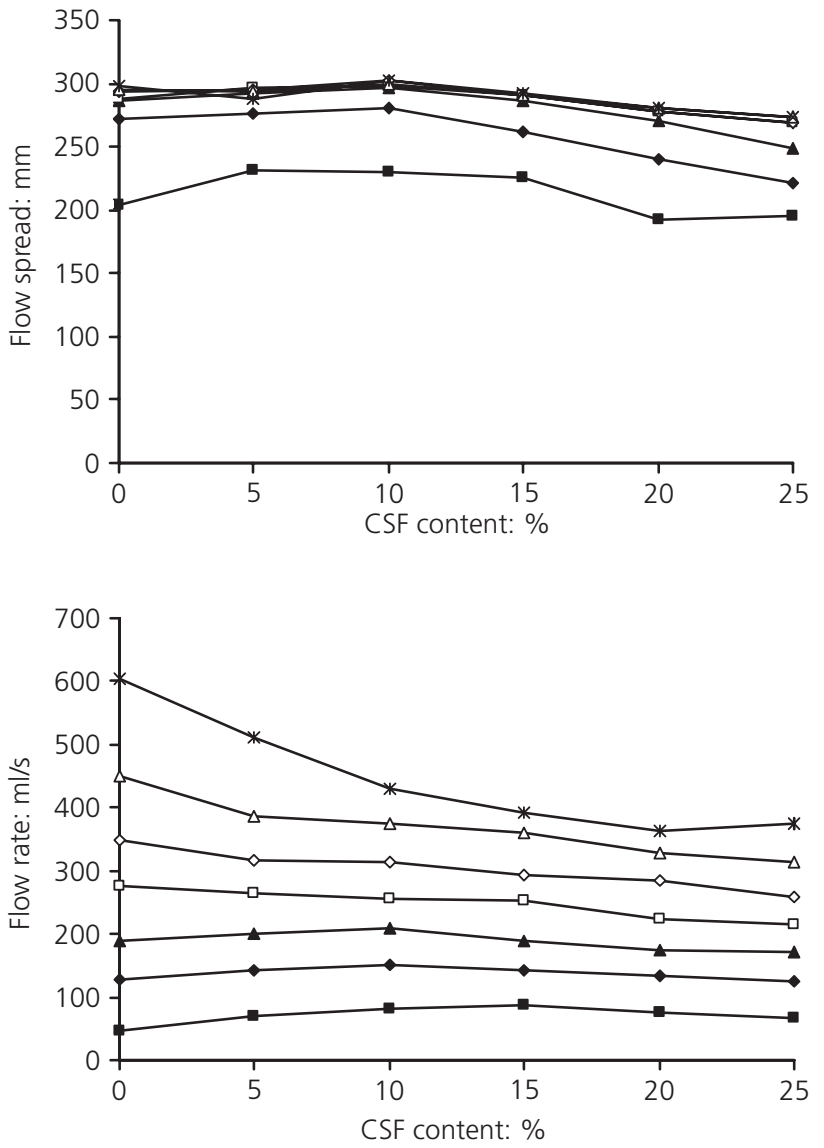

\begin{tabular}{lllll}
$\rightarrow$ & w/s ratio $=0.35$ & $\multimap$ & w/s ratio $=0.55$ \\
$\rightarrow$ & w/s ratio $=0.40$ & $\rightarrow$ & w/s ratio $=0.60$ \\
$\rightarrow$ & w/s ratio $=0.45$ & $\rightarrow$ & w/s ratio $=0.65$ \\
$\rightarrow$ & w/s ratio $=0.50$ & & \\
\hline
\end{tabular}

Figure 7. Flowability plotted against CSF content

content increased from $0 \%$ onwards, the yield stress first decreased to a minimum value at an optimum CSF content of around $10 \%$ and then increased. Such effect of CSF on yield stress was smaller at a higher $\mathrm{w} / \mathrm{s}$ ratio and became negligible at w/s ratios higher than $0 \cdot 50$. Conversely, the apparent viscosityCSF content curves reveal that at a w/s ratio equal to $0 \cdot 35,0 \cdot 40$ or $0 \cdot 45$, the apparent viscosity first decreased to a minimum value and then increased as the CSF content increased from $0 \%$ onwards while at a w/s ratio equal to 0.50 or higher, the apparent viscosity constantly and slightly increased as the CSF content increased. Therefore, the effects of CSF on yield stress and apparent viscosity are dependent on the $\mathrm{w} / \mathrm{s}$ ratio. At a w/s ratio lower than $0 \cdot 50$, the addition of CSF could reduce the yield stress and apparent viscosity whereas at a $\mathrm{w} / \mathrm{s}$ ratio higher than 0.50 , the addition of CSF would either have little effect or slightly increase the yield stress and apparent viscosity. This explains why different results on the effects of CSF have been obtained by different researchers. 
Effects of CSF content on rheology and cohesiveness of mortar

Kwan and Fung
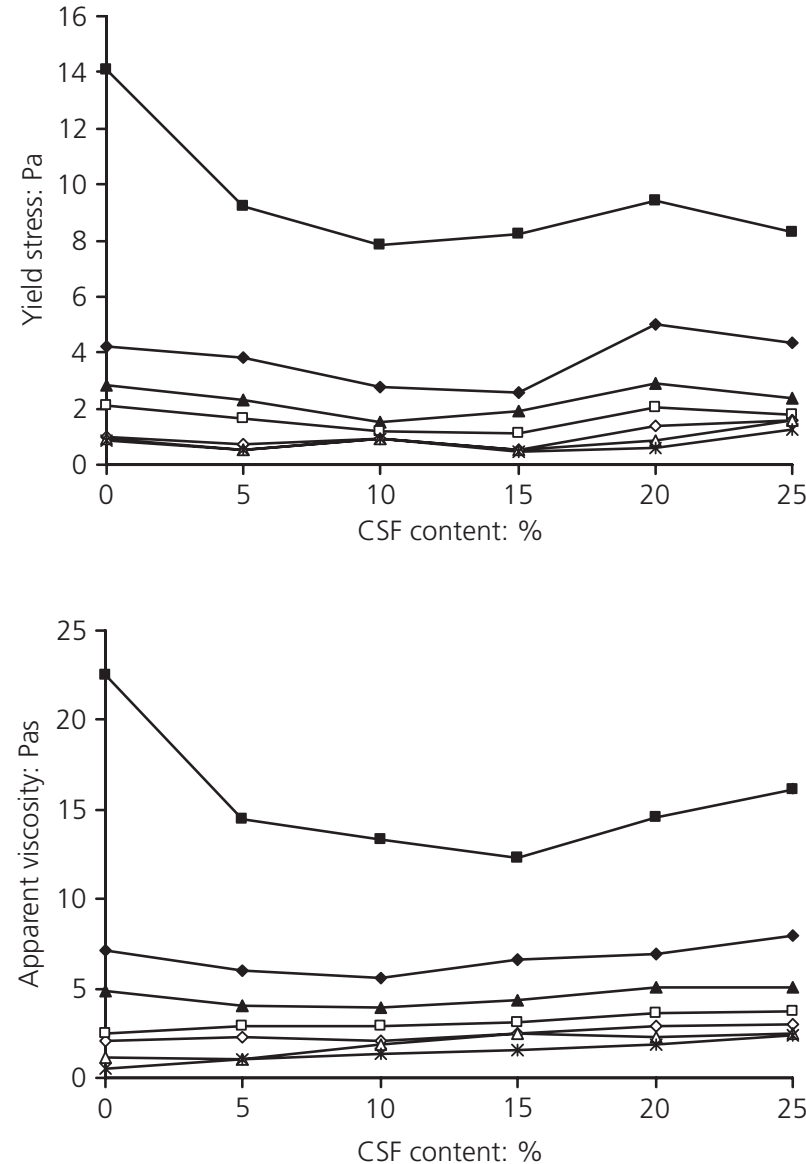

$\begin{array}{lllll}\rightarrow- & \text { w/s ratio }=0.35 & \multimap & \text { w/s ratio }=0.55 \\ \longrightarrow & \text { w/s ratio }=0.40 & \rightarrow & \text { w/s ratio }=0.60 \\ \rightarrow & \text { w/s ratio }=0.45 & \rightarrow & \text { w/s ratio }=0.65 \\ \rightarrow & \text { w/s ratio }=0.50 & & \end{array}$

Figure 8. Rheological properties plotted against CSF content

The beneficial effects of CSF may be attributed to the increase in packing density. With the packing density increased due to the addition of CSF, the amount of water needed to fill up the voids between the solid particles would be decreased and the amount of excess water available for lubricating the mortar would be increased. On the other hand, the adverse effects of CSF may be attributed to the increase in solid surface area. With the solid surface area increased due to the addition of CSF, the thickness of the water films coating the solid particles for lubrication would be decreased. Since it is actually the water film thickness that determines the flowability and rheological properties of mortar, the net effect of CSF is dependent on the relative magnitudes of the above beneficial and adverse effects. Basically, the test results show that when the w/s ratio is lower than 0.50 and the CSF content is not higher than $15 \%$, the beneficial effect is larger but when the w/s ratio is higher than $0.50 \mathrm{and} /$ or the CSF content is higher than $15 \%$, the adverse effect is larger.

Finally, to study the effects of CSF on the cohesiveness, the SSI results are plotted against the CSF content in Figure 9. The graph shows that at all w/s ratios covered in the study, the SSI always decreased as the CSF content increased. When the w/s ratio was low (say, equal to $0.35,0.40$ or 0.45 ), the reduction in SSI owing to addition of CSF was relatively small but when the w/s ratio was high (say, equal to or higher than 0.50), the reduction in SSI due to addition of CSF became quite substantial. During the mortar tests, it was observed that the mortar samples with SSI higher than $10 \%$ generally showed certain signs of segregation and bleeding. Hence, an upper limit of $10 \%$ should be set to the SSI in order to ensure that the mortar has sufficient cohesiveness to avoid segregation. With this upper limit set, the CSF content for achieving sufficient cohesiveness - that is, achieving an SSI of not higher than $10 \%$, may be determined from Figure 9. For example, at a w/s ratio of $0 \cdot 40$, no CSF is needed to achieve an SSI of not higher than $10 \%$ but at a w/s ratio of $0 \cdot 60$, up to $20 \%$ CSF is needed to achieve an SSI of not higher than $10 \%$. Generally, a mortar with a higher w/s ratio would need more CSF for achieving sufficient cohesiveness.

\section{Overall flowability-cohesiveness performance}

As demonstrated in the previous sections, the addition of CSF could, under certain conditions, improve the flowability, rheological properties and cohesiveness at the same time. For example, at a w/s ratio of 0.45 , the addition of $10 \%$ CSF could increase the flow spread from 286 to $297 \mathrm{~mm}$ and the flow rate from 188 to $210 \mathrm{ml} / \mathrm{s}$, and decrease the yield stress from 2.86 to $1.51 \mathrm{~Pa}$, the apparent viscosity from 4.85 to 3.89 Pas, and the SSI from 11.2 to $5 \cdot 5 \%$, as shown in Table 2 . However, detailed analysis of the test results reveals that such simultaneous improvement in flowability, rheological properties and cohesiveness is possible only when the w/s ratio is not higher than $0 \cdot 45$. When the w/s

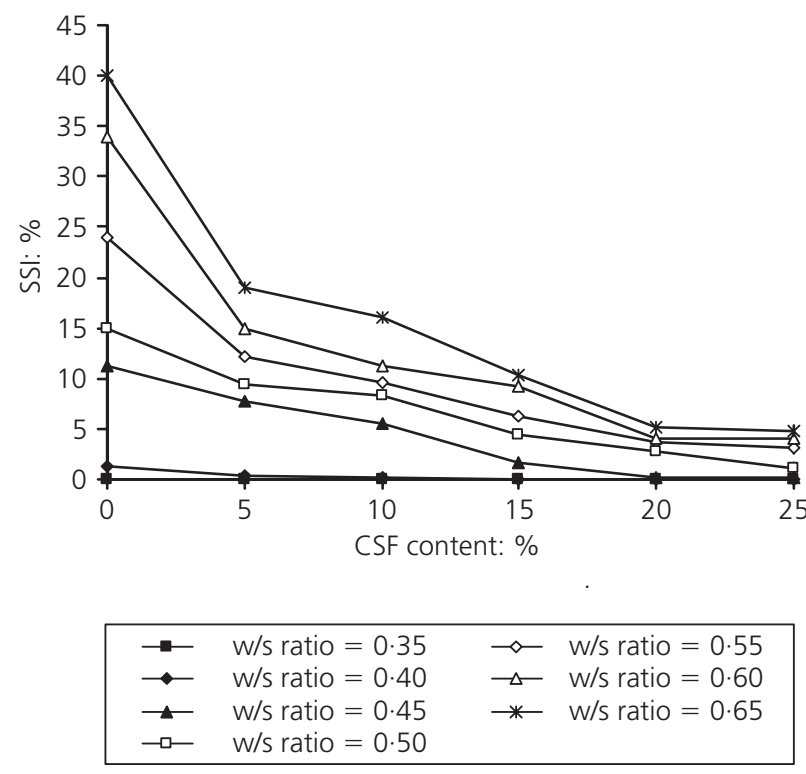

Figure 9. Sieve segregation index plotted against CSF content 
ratio is higher than $0 \cdot 45$, the addition of CSF would rather impair the flowability and rheological properties.

Nevertheless, even at a w/s ratio higher than $0 \cdot 45$, the addition of CSF could be beneficial to the overall performance. In assessing the overall performance of a mortar, both the flowability and cohesiveness should be considered. Although the addition of CSF could sometimes impair the flowability, it would always improve the cohesiveness. The overall flowability-cohesiveness performance may be studied by plotting the concurrently achieved flow rate and SSI for each CSF content, as in Figure 10. Each performance curve so plotted demarcates the limits of concurrent flowability and cohesiveness that can be achieved at a given CSF content. From these curves, it is evident that an increase of CSF content would shift the curve downwards and to the right. Such shifting of the curve reveals that the addition of CSF could at the same SSI (or cohesiveness), increase the flow rate or at the same flow rate, decrease the SSI (or increase the cohesiveness).

An alternative way of evaluating the overall performance is to determine the maximum flow rate without segregation, which may be defined as the flow rate at the upper acceptable SSI limit of $10 \%$. The maximum flow rate without segregation may be determined from the curves plotted in Figure 10 by interpolation. For example, the maximum flow rate without segregation for the mortar containing no CSF can be estimated as $181 \mathrm{ml} / \mathrm{s}$ while that for the mortar containing $15 \% \mathrm{CSF}$ can be estimated as $382 \mathrm{ml} / \mathrm{s}$. The substantial increase in the maximum flow rate without segregation indicates that regardless of the w/s ratio, the addition of CSF can always increase the flow rate without causing segregation.

\section{Correlation between flowability and rheological \\ properties}

The flow spread, flow rate, yield stress and apparent viscosity are to some extent interrelated. To demonstrate their interrelationship, the flow spread results are plotted against the yield stress results

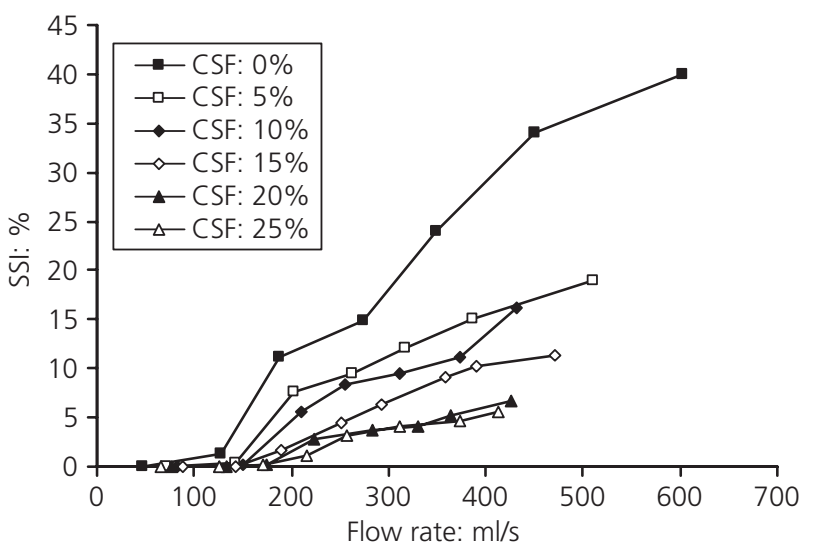

Figure 10. Sieve segregation index plotted against flow rate in Figure 11 and the flow rate results are plotted against the apparent viscosity results in Figure 12.

The flow spread-yield stress curves in Figure 11 show that the flow spread generally decreased as the yield stress increased. However, the flow spread-yield stress relation is not unique. For different CSF contents, different flow spread-yield stress curves are obtained. This indicates that the flow spread-yield stress relation is dependent on the CSF content. Basically, at a higher CSF content, the flow spread-yield stress curve is lower. Hence, at the same yield stress, a higher CSF content would result in a smaller flow spread. During the mini slump cone tests, it was observed that with a higher CSF content, the mortar patty formed was thicker because of its higher cohesiveness. Quite possibly, it was the larger thickness of the mortar patty formed that had resulted in a smaller flow spread at a higher CSF content. So apparently, the flow spread, as a measurement of flowability, is interfered by the cohesiveness of the mortar.

The flow rate-apparent viscosity curves in Figure 12 show that likewise the flow rate generally decreased as the apparent

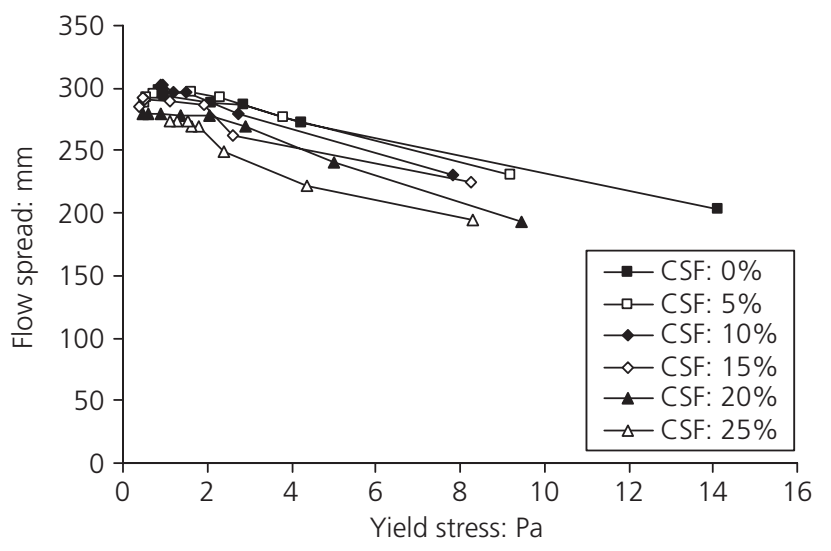

Figure 11. Flow spread plotted against yield stress

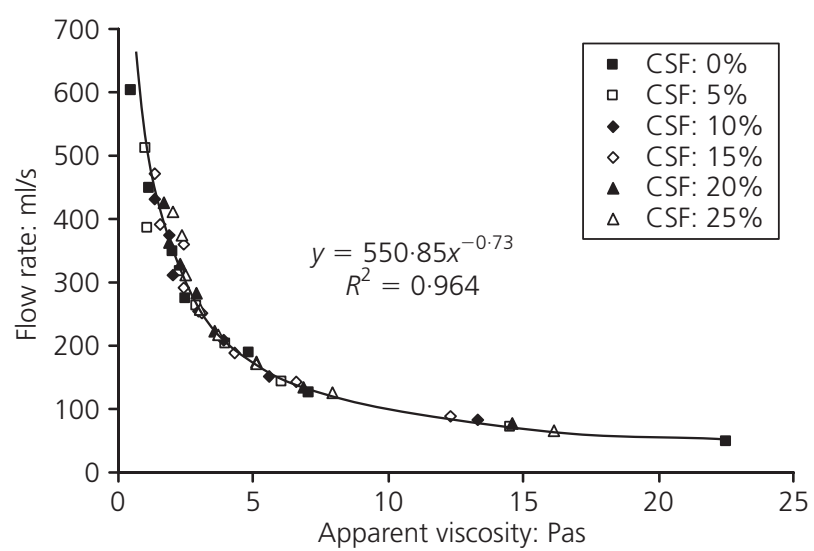

Figure 12. Flow rate plotted against apparent viscosity 
viscosity increased. This time, the flow rate-apparent viscosity relation is very unique. Regardless of the CSF content, the same flow rate-apparent viscosity curve is obtained. This indicates that the flow rate-apparent viscosity relation is not dependent on the CSF content. Regression analysis of the correlation between the flow rate and apparent viscosity has produced an $R^{2}$ value of 0.964 . This strong correlation suggests that the flow rate, being governed solely by the apparent viscosity, is almost equivalent to the apparent viscosity. Hence, the flow rate, which can be measured more easily by the mini V-funnel test, may be taken as an alternative measure of the apparent viscosity.

\section{Conclusions}

A total of 45 mortar samples proportioned with different CSF contents and different $\mathrm{w} / \mathrm{s}$ ratios were produced for packing density, flowability, rheological properties and cohesiveness measurements. For the packing density measurement, the wet packing test was applied. Furthermore, the flowability was measured by the mini slump cone and mini V-funnel tests while the rheological properties were measured by the vane test using a speedcontrolled rheometer. Finally, the cohesiveness was measured by a modified sieve segregation test. Based on the test results so obtained, the effects of CSF on the fresh properties of mortar were investigated.

The measured packing density varied from 0.712 to 0.767 , amounting to about $8 \%$ difference. Since the cementitious materials to fine aggregate ratio was fixed, the variation in packing density was due solely to the filling effect of CSF. This is the first time that the increase in packing density of mortar due to addition of CSF was directly measured. Despite being small, such variation in packing density can have great effects on the mortar, and, therefore, the packing density must be measured as accurately as possible. On the whole, the test results revealed that both the $\mathrm{w} / \mathrm{s}$ ratio and CSF content have major effects on the fresh properties of mortar. As expected, a higher w/s ratio would improve the flowability and rheological properties but would also reduce the cohesiveness needed to avoid segregation. However, the effects of the CSF content were fairly complicated.

In-depth analysis showed that the effects of CSF content were dependent on the w/s ratio. At a w/s ratio not higher than $0 \cdot 45$, there was an optimum CSF content at which the flowability was highest and the rheological properties were lowest. At a w/s ratio higher than $0 \cdot 45$, both the flowability and rheological properties were impaired by the addition of CSF. In contrast, regardless of the $\mathrm{w} / \mathrm{s}$ ratio, the cohesiveness was always improved by the addition of CSF. In any case, it is evident from the concurrent flowability and cohesiveness achieved at different CSF contents that the addition of CSF could at the same cohesiveness increase the flowability or at the same flowability increase the cohesiveness. Hence, the addition of CSF would improve the overall flowability-cohesiveness performance of mortar.
Regarding the test methods, the wet packing test previously developed by the authors' research group was successfully extended to apply to mortar containing CSF. The modified sieve segregation test, though still rudimentary, turned out to be quite successful as a simple test for measuring the cohesiveness of mortar. Finally, the flow spread and flow rate have been correlated to the yield stress and apparent viscosity, respectively. It was found that the correlation between the flow spread and yield stress is dependent on the CSF content, due probably to the interference of cohesiveness. However, the correlation between the flow rate and apparent viscosity is very unique and not dependent on the CSF content, indicating that the flow rate is almost equivalent to the apparent viscosity.

\section{Acknowledgement}

The work described in this paper was fully supported by a grant from the Research Grants Council of the Hong Kong SAR, China (Project No. 713309).

\section{REFERENCES}

Aïtcin P-C (1998) High-Performance Concrete. E \& FN Spon, London.

Artelt C and Garcia E (2008) Impact of superplasticizer concentration and of ultra-fine particles on the rheological behaviour of dense mortar suspensions. Cement and Concrete Research 38(5): 633-642.

ASTM (American Society for Testing and Materials) (2003) ASTM C 1240-03. Standard specification for use of silica fume as a mineral admixture in hydraulic cement concrete, mortar and grout. ASTM, West Conshohocken, PA, USA.

BSI (British Standards Institution) (1995) BS 812. Part 2. Testing aggregates - methods for determination of density. BSI, London.

BSI (1996) BS 12. Specification for Portland cement. BSI, London.

Domone P (2006) Mortar tests for self-consolidating concrete. Concrete International 28(4): 39-45.

Duval R and Kadri EH (1998) Influence of silica fume on the workability and the compressive strength of highperformance concretes. Cement and Concrete Research 28(4): $533-547$.

Fung WWS, Kwan AKH and Wong HHC (2009) Wet packing of crushed rock fine aggregate. Materials and Structures 42(5): 631-643.

Gołaszewski J and Szwabowski J (2004) Influence of superplasticizers on rheological behaviour of fresh cement mortars. Cement and Concrete Research 34(2): 235-248.

Khatri RP, Sirivivatnanon V and Gross W (1995) Effect of different supplementary cementitious materials on mechanical properties of high performance concrete. Cement and Concrete Research 25(1): 209-220.

Kohno K and Komatsu H (1986) Use of ground bottom ash and silica fume in mortar and concrete. Proceedings of the 2nd International Conference on Fly Ash, Silica Fume, Slag, and Natural Pozzolans in Concrete (Malhotra VM (ed.)). Special 
Publication SP-91, American Concrete Institute, Madrid, Spain, 1279-1292.

Kwan AKH and Fung WWS (2009) Packing density measurement and modelling of fine aggregate and mortar. Cement and Concrete Composites 31(6): 349-357.

Lachemi M, Hossain KMA, Patel R, Shehata M and Bouzoubaâ N (2007) Influence of paste/mortar rheology on the flow characteristics of high-volume fly ash self-consolidating concrete. Magazine of Concrete Research 59(7): 517-528.

Ng IYT, Ng PL and Kwan AKH (2009) Rheology of mortar and its influences on performance of self-consolidating concrete. Key Engineering Materials 400-402: 421-426.

Nkinamubanzi P-C and Aïtcin P-C (2004) Cement and superplasticizer combinations: compatibility and robustness. Cement, Concrete and Aggregates 26(2): 102-109.

Okamura H and Ouchi M (2003) Self-compacting concrete. Journal of Advanced Concrete Technology 1(1): 5-15.

Park CK, Noh MH and Park TH (2005) Rheological properties of cementitious materials containing mineral admixtures. Cement and Concrete Research 35(5): 842-849.

Radjy FF, Bogen T, Sellevold EJ and Loeland KE (1986) A review of experiences with condensed silica-fume concretes and products. Proceedings of the 2nd International Conference on Fly Ash, Silica Fume, Slag, and Natural Pozzolans in Concrete (Malhotra VM (ed.)). Special Publication SP-91, American Concrete Institute, Madrid, Spain, 1135-1152.

Rao GA (2003) Investigations on the performance of silica fumeincorporated cement pastes and mortars. Cement and Concrete Research 33(11): 1765-1770.

Safawi MI, Iwaki I and Miura T (2004) The segregation tendency in the vibration of high fluidity concrete. Cement and Concrete Research 34(2): 219-226.

SCC European Project Group (2005) The European Guidelines for Self-Compacting Concrete. BIBM, CEMBUREAU, EFCA, EFNARC and ERMCO, (SCC European Project Group).

Vikan $\mathrm{H}$ and Justnes $\mathrm{H}$ (2007) Rheology of cementitious paste with silica fume or limestone. Cement and Concrete Research 37(11): 1512-1517.

Wong HHC and Kwan AKH (2008) Packing density of cementitious materials: part 1 - measurement using a wet packing method. Materials and Structures 41(4): 689-701.

Zhang $X$ and Han J (2000) The effect of ultra-fine admixture on the rheological property of cement paste. Cement and Concrete Research 30(5): 827-830.

\section{WHAT DO YOU THINK?}

To discuss this paper, please submit up to 500 words to the editor at www.editorialmanager.com/macr by 1 August 2011. Your contribution will be forwarded to the author(s) for a reply and, if considered appropriate by the editorial panel, will be published as a discussion in a future issue of the journal. 